\title{
REGULATION OF PGK1
}

4

5

Junkyu Han $^{1,2}$, Yusaku Miyamae ${ }^{1}$, Hideyuki Shigemori ${ }^{1}$, Hiroko Isoda ${ }^{1,2 *}$

6

$7 \quad{ }^{1}$ Graduate School of Life and Environmental Sciences, ${ }^{2}$ Alliance for Research on North 
1 Abbreviations: $A \beta, \beta$-amyloid protein; $A D$, Alzheimer's disease; ALS, amyotrophic

2 lateral sclerosis; AO, antisense oligonucleotide; ATCC, American Type Culture Collection;

3 BBB, blood-brain barrier; CA, caffeoylquinic acid; CBB, coomassie brilliant blue; CQA,

4 caffeoylquinic acid; IEF, isoelectric focusing; MALDI-ToF, matrix assisted laser

5 desorption ionization-time of flight; MWM, Morris water maze; SAMP, senescence-

6 accelerated-prone mice; SAMR, senescence-accelerated-resistant mice; PGK1,

7 phosphoglycerate kinase-1; THP, tetrahydropapaveroline.

8

9

10

11

12

13

14

15

16

17

18

19

20

21

22 
1 Abstract-As aged population dramatically increases in these decades, efforts should be

2 made on the intervention for curing age-associated neurologic degenerative diseases such

3 as Alzheimer's disease (AD). Caffeoylquinic acid (CQA), an antioxidant component and its

4 derivatives are natural functional compounds isolated from a variety of plants. In this study,

5 we determined the neuroprotective effect of 3,5-di-O-CQA on $A \beta_{1-42}$ treated SH-SY5Y

6 cells using MTT assay. To investigate the possible neuroprotective mechanism of 3,5-di-O-

7 CQA, we performed proteomics analysis, real-time PCR analysis and measurement of the

8 intracellular ATP level. In addition, we carried out the measurement of escape latency time

9 to find the hidden platform in Morris water maze (MWM), real-time PCR using

10 senescence-accelerated-prone mice (SAMP) 8 and senescence-accelerated-resistant mice

11 (SAMR) 1 mice. Results showed that 3,5-di-O-CQA had neuroprotective effect on A $\beta_{1-42}$

12 treated cells. The mRNA expression of glycolytic enzyme (phosphoglycerate kinase-1;

13 PGK1) and intracellular ATP level were increased in 3,5-di-O-CQA treated SH-SY5Y cells.

14 We also found that 3,5-di-O-CQA administration induced the improvement of spatial 15 learning and memory on SAMP8 mice, and the overexpression of PGK1 mRNA. These

16 findings suggest that 3,5-di-O-CQA has a neuroprotective effect on neuron through the 17 upregulation of PGK1 expression and ATP production activation.

22 Keywords: 3,5-di-O-caffeoylquinic acid, SH-SY5Y, SAMP8, PGK1, Glycolysis, ATP 
1 The major reason of aging is the functional decrease of energy production in the body.

2 Aging is usually associated with the accumulation of reactive oxygen species (ROS)-

3 mediated oxidative damage, which can induce the decrease in intracellular ATP levels via

4 the functional decline of mitochondrion. Intracellular ATP depletion causes cell death in

5 neuronal cells, leading to neurodegenerative diseases such as Alzheimer's disease (AD),

6 amyotrophic lateral sclerosis (ALS) and Parkinson's disease (Beal et al., 1995; Huaug et al.,

7 2001). AD, in particular, is one of the diseases with increasing number of patients with age-

8 related neurodegenerative disorders, and is a degenerative disorder of the central nervous

9 system, which causes mental deterioration and progressive dementia. AD is accompanied

10 by neuropathologic lesions including the presence of senile plaques of the $\beta$-amyloid

11 protein $(\mathrm{A} \beta)$, an etiological role in $\mathrm{AD}$. The overexpression of $\mathrm{A} \beta$ protein and its fibrillar

12 deposition in senile plaques have been correlated with the progression of cognitive

13 impairment in AD (Eckert et al., 2003; Roth, 2001; Holliday, 1996).

14 One of the animal models that is used to study AD and aging is the senescence15 accelerated mouse (SAM). The SAM model was developed in 1981, which originally 16 consisted of nine major senescence-accelerated-prone mice (SAMP) substrains and three 17 major senescence-accelerated-resistant mice (SAMR) substrains, each of which exhibits the 18 characteristic disorders. Thereafter, selective inbreeding was applied based on the degree of 19 senescence, the lifespan, and the age-associated pathologic phenotypes (Hosokawa et al., 20 1997; Takeda et al., 1981). The SAMP8 strain exhibits age-related deterioration in memory

21 and learning (Yagi et al., 1988; Ohta et al., 1989) along with the overexpression of amyloid 22 precursor protein (APP) (Li et al., 2009; Nomura et al., 1996; Morley et al., 2000). SAMP8 
1 mice also show decreased glucose metabolism (Poon et al., 2005; Shimano, 1998), which is

2 a characteristic of AD wherein energy metabolism is impaired (Blass et al., 1988). The

3 decrease in the production of $A \beta$, after giving an intracerebroventricular injection of a 42-

4 mer phosphorothiolated antisense oligonucleotide (AO) directed at the $\mathrm{A} \beta$ region of the

5 APP gene, can reduce lipid peroxidation and protein oxidation and improve cognitive

6 deficits in aged SAMP8 mice. Therefore, SAMP8 is a good model to study brain aging and

7 is used as one mouse model of AD.

8 Caffeoylquinic acid (CQA) derivatives are natural functional compounds isolated

9 from a variety of plants and possess a broad range of pharmacological properties,

10 including antioxidant, hepatoprotectant, antibacterial, antihistaminic, anticancer, and

11 other biological effects (Basnet et al., 1996; Kwon et al., 2000; Nakajima et al., 2005).

12 Recently, it has been demonstrated that CQA derivatives possess neuroprotective

13 effects in A $\beta$-induced PC12 cell toxicity (Hur et al., 2001) and in tetrahydropapaveroline

14 (THP)-induced C6 glioma cell death (Soh et al., 2003). Moreover, CQA exhibited a

15 neuroprotective function against in vitro cell death and in vivo ischemia-induced neuronal

16 damage. However, the mechanism by which these caffeoylquinic acid derivatives exert

17 neuroprotection is unclear.

18 In this study, we used a SH-SY5Y human neuroblastoma cell line as the A $\beta$ -

19 induced neuronal cell death model and the SAMP8 mice as the in vivo AD model, to

20 determine a pharmacological function for the the neuroprotective properties of 3,5-di CQA.

21 Furthermore, to investigate the mechanism for the neuroprotective effect of 3,5-di CQA, we

22 have performed (2D)-polyacrylamide-gel electrophoresis (PAGE), matrix assisted laser 
1 desorption ionization-time of flight (MALDI-ToF) mass spectrometry analysis and real

2 time PCR.

3

\section{EXPERIMENTAL PROCEDURRS}

\section{Cell culture}

6 The human neuroblastoma clonal SH-SY5Y cell line was obtained from American Type

7 Culture Collection (ATCC). Cultures were maintained in serum-containing medium (1:1

8 mixture of Dulbecco's modified Eagle's medium and Ham's nutrient mixture F-12), 9 supplemented with $15 \%$ fetal bovine serum and MEM non-essential amino acids. Cells 10 were maintained at $37^{\circ} \mathrm{C}$ under $5 \% \mathrm{CO}_{2} / 95 \%$ air. To culture for the subsequent extraction 11 of protein and total RNA, cells were seeded onto Petri plates at a density of $2 \times 10^{6}$ cells per 12 dish, and 3,5-di-O-CQA was added at a final concentration of $20 \mu \mathrm{M}$.

\section{Determination of cell viability}

15 To investigate the neuroprotective effect, we employed the A -treated SH-SY5Y cell 16 model ( $\mathrm{Li}$ et al., 1996; Wang et al., 2009). Cell viability was assessed using the

17 conventional MTT reduction assay. The cultured cells in 96-well plates (fibronectin coated 18 plate) were treated with 3,5-di-O-CQA and exposed to $2 \mu \mathrm{M} \mathrm{A} \beta_{1-42}$ for $72 \mathrm{~h}$, then $10 \mu \mathrm{l}$ of 19 MTT stock solution (5 mg/ml) was added to the culture medium and incubated for $6 \mathrm{~h}$ at $2037^{\circ} \mathrm{C}$. The formazan was extracted with $100 \mu \mathrm{l} 10 \%$ SDS (W/V) and the absorbance was 21 measured with a microtiter plate reader. 


\section{Two-dimensional gel electrophoresis (2-DE)}

2 2-DE was performed essentially as described by Isoda et al. (2006) with modifications.

3 Samples containing $30 \mu \mathrm{g}$ for analytical gels or $300 \mu \mathrm{g}$ for preparative gels of protein were

4 separated by isoelectric focusing (IEF) and then by sodium dodecyl sulfate polyacrylamide

5 gel eletrophoresis (SDS-PAGE) using Ettan IPGphor II and Ettan DALTsix (GE Healthcare,

6 Uppsala, Sweden). For IEF, samples were added into the rehydration solution containing 8

7 M urea, 2\% CHAPS, 0.5\% IPG buffer, 0.002\% bromophenol blue and 0.28\% (w/v)

8 dithiothreitol (DTT), and then applied to a 24cm immobiline dry strips, which are dry

9 polyacrylamide gel strips with an immobilized $\mathrm{pH}$ gradient $\mathrm{pH}$ 3-10 (GE Healthcare). The

10 dry strips were rehydrated at $20{ }^{\circ} \mathrm{C}$ for $12 \mathrm{~h}$ and isoelectric focusing of proteins was carried

11 out at $500 \mathrm{~V}$ for $1 \mathrm{~h}, 1000 \mathrm{~V}$ for $1 \mathrm{~h}, 10000 \mathrm{~V}$ for $3 \mathrm{~h}, 10000 \mathrm{~V}$ for $2 \mathrm{~h}$, and, $45 \mathrm{~min}$.

12 Thereafter, IPG strips were reduced (1\% DTT) and alkylated (2.5\% iodoacetamide) in

13 equilibration buffer (6 $\mathrm{M}$ urea, $50 \mathrm{mM}$ Tris-Cl, $\mathrm{pH}$ 8.8, 30\% glycerol, 2\% SDS). When the

14 equilibration was finished, the strips were loaded onto $12 \%$ acrylamide vertical gels and

15 separation of proteins with different molecular weight was carried out at $2.5 \mathrm{~W}$ per gel for

$1630 \mathrm{~min}$, followed by $25 \mathrm{~W}$ per gel for $3.5 \mathrm{~h}$.

17 Silver staining using Plus One Silver Staining Kit (GE Healthcare) was performed

18 according to the manufacturer's instructions. The stained gels were subjected to image

19 analysis by ImageMaster 2D Platinum software (ver. 4.9; GE Healthcare). Gels in which

20 proteins from either $\beta$-amyloid (A $\beta$ ) or caffeoylquinic acid (CA) treatment, or both, as well

21 as control were imported into the same platform and were subjected to image analysis.

22 After spot detection and matching, the spots of interest were manually selected and the 
1 data regarding the relative intensities of these spots were obtained. Spots intensities were

2 expressed as percentages (\% vol) of relative volumes by integrating the value (or OD) of

3 each pixel in the spot area (vol) and dividing it with the sum of the volumes of all the spots

4 detected in the gel.

5

$6 \quad$ In-gel digestion and mass spectrometry

7 For spot picking, preparative gels in which quantity of protein was ten times more than that

8 in analytical gels, were prepared. After coomassie brilliant blue (CBB) staining using

9 Coomassie Tablets, PhastGel R-350 (GE Healthcare), the protein spots of interest were

10 excised and put into $1.5 \mathrm{ml}$ eppendorf tubes. After destaining, the spots were digested with

11 trypsin (sequencing grade, GE Healthcare) and the peptides were extracted. Prior to

12 analysis on mass spectrometer, the peptide solutions were desalted by Zip Tip C18

13 (Millpore, Tokyo, Japan). The peptide solutions were then applied onto MALDI plate

14 directly and the solution drop was allowed to air-dry. Furthermore, the matrix solution,

15 prepared by dissolving $10 \mathrm{mg}$ of $\alpha$-cyano-4-hydroxycinnamic acid (CHCA, Sigma, USA)

16 in $1 \mathrm{ml}$ of $50 \%$ acetonitrile and $0.1 \%$ triflouroacetic acid in deionized water, was overlayed

17 onto the dried drops. After the matrix solution was dried, the plate was inserted into the

18 MALDI-TOF mass spectrometer and was subjected to peptide mass fingerprinting. All the

19 MALDI-TOF mass spectra were acquired on AXIMA-CFR mass spectrometer. The

20 acquired MS spectra were searched against NCBI database using the MASCOT

21 (www.matrixscience.com) MS search engine. The search parameters were the following:

22 type of search, peptide mass fingerprint; enzyme, trypsin; fixed modification, 
1 carbamidomethyl (C); variable modifications, oxidation (M); mass values, monoisotopic;

2 protein mass, unrestricted; peptide mass tolerance, 0.2 Da; peptide charge state, 1 ; max

3 missed cleavages, 2.

\section{Real-time PCR}

6 To find the trigger genes on the neuroprotective effect of 3,5-di-O-CQA, we considered the

7 lower concentration (10 $\mu \mathrm{M})$ and shorter treatment time (16 h). After incubating seeded

8 plates for 16 h, total RNA was purified using the ISOGEN kit (Nippon Gene Co. Ltd.,

9 Japan). Total RNA was quantified by measurement of the spectrophotometer at $260 \mathrm{~nm}$

10 with a UV spectrophotometer and was also measured at $280 \mathrm{~nm}$ to assess purity. Only RNA

11 with a 260/280 ratio higher than 1.8 was used for real-time PCR. The template cDNA was

12 synthesized from total RNA using the SuperScript reverse transcriptase system (Invitrogen).

13 Briefly, RNA was denatured at $65{ }^{\circ} \mathrm{C}$ for 5 min and incubated with $1 \mu \mathrm{L}$ oligo (dT) ${ }_{12-15}$

14 primers and chilled at $4^{\circ} \mathrm{C}$. After adding SuperScript II reverse transcriptase (200 units) the

15 reaction mix was incubated at $42^{\circ} \mathrm{C}$ for $60 \mathrm{~min}$, then $10 \mathrm{~min}$ at $70^{\circ} \mathrm{C}$ (16). For the

16 quantification of mRNA, nested primers were designed using Primer3 input software

17 (http://frodo.wi.mit.edu/cgi-bin/primer3/ primer3.cgi/primer3_www.cgi). Quantitative PCR

18 reactions were performed in a MiniOpticon instrument (Bio-Rad, USA) and carried out as

19 recommended for iQ SYBRGreen supermix (Bio-Rad). Briefly, the RT mix (2 $\mu \mathrm{L})$ was

20 used as template for the real-time PCR mix containing $0.5 \mathrm{mM}$ forward (5'

21 ACAATGGAGCCAAGTCGGTAG-3')

22 GCCTACACAGTCCTTCAAGAAC-3') nested primers (2 $\mu \mathrm{L}$ each) and 2 x SYBR Green 
1 supermix $(10 \mu \mathrm{L})$. The amplification conditions were: 3 min at $95^{\circ} \mathrm{C}, 10 \mathrm{~s}$ at $95^{\circ} \mathrm{C}, 30 \mathrm{~s}$ at

$262^{\circ} \mathrm{C}$, and $30 \mathrm{~s}$ at $72^{\circ} \mathrm{C}$ for 34 cycles. At the end of the reaction, a melting curve analysis

3 was carried out to check for the presence of primer-dimers.

4

\section{Measurement of Intracellular ATP Content.}

6 ATP was assessed as firefly bioluminescence using the luminescence luciferase assay kit

7 (TOYO Ink, Tokyo, Japan). To determine the increase of intracellular ATP content due to

8 3,5-di-O-CQA treatment SH-SY5Y cells $\left(2 \times 10^{3}\right.$ cells/well) were pretreated for $48 \mathrm{~h}$ with

9 3,5-di-O-CQA (10 and $20 \mu \mathrm{M}$ ) after which, cells were lysed with $100 \mu \mathrm{L}$ of lysis buffer

10 (Toyo ink) and placed directly into the chamber of a luminometer (Powerscan HT;

11 Dainippon Pharmaceutical, Osaka, Japan). Light emission was recorded after the addition

12 of $100 \mu \mathrm{L}$ of luciferin-luciferase solution (Toyo ink). When ATP is the limiting component

13 in a luciferase reaction, the intensity of light emitted is proportional to the concentration of

14 ATP in the cytosolic extracts.

15

16 Animals and supplementation

17 Male SAMP8 and SAMR1 mice were provided by the Japan SLC company. Three mice 18 were housed per cage with a 12-h light/dark cycle. The animals had free access to food and 19 water. After a 7-day acclimatization to the laboratory conditions, 3 month old SAMP8 mice 20 ( $n=20)$ were randomly divided into two groups: SAMP8 control group $(n=10)$, 3,5-di-O21 CQA-supplemented group ( $n=10)$, while age matched SAMR1 mice $(n=10)$ served as the 22 normal aging control. The 3,5-di-O-CQA-treated mice were orally administered with 3,5- 
1 di-O-CQA mixed with drinking water $(6.7 \mathrm{mg} / \mathrm{kg} \cdot$ day $)$ for 1 month using oral

2 administration tube and syringe.

4 Morris water maze (MWM)

5 After the open field test, the MWM was selected as a method for the evaluation of the

6 spatial learning and memory. A circular water tank $(120 \mathrm{~cm}$ in diameter and $50 \mathrm{~cm}$ in

7 height) was filled with water to a depth of $30 \mathrm{~cm}$. Inside the tank, an escape platform (11

$8 \mathrm{~cm}$ in diameter) was placed, with the top of $1 \mathrm{~cm}$ below the water surface. The platform

9 was in the middle of the target quadrant, and its position remained fixed during the

10 experiment. Above the tank, a white floor-to-ceiling cloth curtain was drawn around the

11 pool, and four kinds of black cardboard (circle, triangular, rhombus and square) were hung

12 equidistantly on the interior of the curtain serving as spatial cues. Each mouse had daily

13 sessions of one trial for 30 consecutive days. When they succeeded, mice were allowed to

14 stay on the platform for $30 \mathrm{~s}$. When the mice failed to find the platform within $60 \mathrm{~s}$, they

15 were assisted by the experimenter and allowed to stay the platform for the same time. A

16 probe trial was performed $24 \mathrm{~h}$ after the last training session. In this trial, the platform was

17 removed from the tank and mice were allowed to swim freely for $60 \mathrm{~s}$.

\section{Statistical analysis}

20 The escape latency of mice in the MWM training was analyzed using the two-way analysis

21 of variance (ANOVA) with repeated measures, the factors being treatment and training day.

22 One-way ANOVA was used to analyze group differences for the data collected in the swim 
1 speed analysis, the MWM probe trial, and the open field test, Nissl staining and Western

2 blotting, followed by LSD (equal variances assumed) or Tamhane's T2 (equal variances not

3 assumed) post hoc tests. A criterion of $P<0.05$ was considered significant and the results

4 were expressed as mean \pm SEM.

\section{RESULTS}

7 Neuroprotective effect of CQA on $A \beta_{1-42}$-induced neuronal death

8 In order to eliminate the possible neuroprotective effect of 3,5-di-O-CQA, we examined the

9 cell viability when treated with 3,5-di-O-CQA and $A \beta_{1-42}$. SH-SY5Y cells were incubated

10 in the presence or in the absence of $2 \mu \mathrm{M} \mathrm{A} \beta_{1-42}$ for $72 \mathrm{~h}$ and the neuronal survival

11 determined by MTT assays. Fig. 1 shows the MTT result of cells treated for $72 \mathrm{~h}$ with 10

$12 \mu \mathrm{M} \mathrm{A} \beta_{1-42}$, and treated with $20 \mu \mathrm{M} 3$,5-di-O-CQA. The cell viability of $\mathrm{A} \beta_{1-42}$ treated cells

13 was significantly decreased to $74.2 \% \pm 7.6$ compared with the non-treated group $(P<0.01)$.

14 In addition, we investigated the effect of 3,5-di-O-CQA on preventing decreased cell

15 viability in SH-SY5Y cells induced by $A \beta_{1-42}$. Incubation with $20 \mu \mathrm{M}$ 3,5-di-O-CQA

16 reversed the $A \beta_{1-42}$-induced cell death and the cell viability significantly increased to

$17106.5 \% \pm 9.8$ compared to the non-treated group $(P<0.01)$. Interestingly, the cell viability

18 of 3,5-di-O-CQA treated cells, without $A \beta_{1-42}$ treatment, significantly increased to $124.6 \%$

$19 \pm 9.8$ compared to the non-treated group $(P<0.01)$

20

21 Effect of CQA and/or A $\beta$ treatment on proteins expression profiles of SH-SY5Y cells 
1 To examine the possible mechanism involved in the neuroprotective effect of 3,5-di-O-

2 CQA on neuronal cells, we performed a proteomics analysis on A $\beta_{1-42}$-treated SH-SY5Y

3 cells with or without 3,5-di-O-CQA treatment. Proteins were extracted from the CQA

4 and/or A $\beta$ treated SH-SY5Y cells, which had been treated for $72 \mathrm{~h}$, and the total proteins

5 separated by 2D-gel electrophoresis. A protein pattern of SH-SY5Y cells is shown in Fig.

6 2A. Approximately 2000 spots were detected in each silver-stained gel, with molecular-

7 mass ranges of 15 to $200 \mathrm{kDa}$ and a pI, that ranges from 3 to 10 . Many spots from CQA

8 and/or A $\beta$-treated SH-SY5Y cells were increased or decreased on each gel. As shown in

9 Fig. 2B, $A \beta_{1-42}$ treatment caused a substantial decrease in a particular spot. However, 3,5-

10 di-O-CQA treatment induced up-regulation of a particular spot under $A \beta_{1-42}$ treatment. The

11 spot protein had a relative molecular mass of $40-45 \mathrm{kDa}$ and an isoelectric point in the

12 range of 7.0-7.6 (Boxed region). To identify this protein, the spot was excised and

13 subjected to tryptic digestion and MALDI-ToF mass spectrometry analysis. The results of

14 the database searches showed that the protein sequence most closely corresponded to that

15 of human phosphoglycerate kinase-1 (PGK1), with matching peptides covering 67\% of 16 PGK1 (281/417 amino acids).

18 Effect of CQA on the mRNA expression level of PGK1

19 In order to determine the effect of 3,5-di-O-CQA on the mRNA expression level of PGK1, 20 which is overexpressed by 3,5-di-O-CQA treatment on protein level, we performed the 21 real-time PCR analysis using $\beta$-actin as a control gene. As shown in Fig. 3, the mRNA 22 expression level of PGK1 was highly increased by $20 \mu \mathrm{M}$ 3,5-di-O-CQA treatment on SH- 
1 SY5Y cells. In fact, the mRNA expression level of PGK1 was significantly upregulated by

$2 \quad 119 \% \pm 7.2$ compared with the non-treated group $(P<0.05)$.

4 Effects of CQA on intracellular ATP production

5 Based on the results of proteomics analysis and real-time PCR, 3,5-di-O-CQA induced the

6 increase in PGK1 expression. The PGK1 protein is one of glycolytic enzymes of glycolysis.

7 To investigate the upregulated glycolytic enzyme’s effects on energy generation, the levels

8 of ATP, which is the end product of glycolysis, were evaluated. ATP is a multifunctional

9 nucleotide that is important as a "molecular currency" of intracellular energy transfer. In

10 this role, ATP transports chemical energy within cells for metabolism. Intracellular ATP

11 production level of 3,5-di-O-CQA-treated SH-SY5Y cells was measured by a luciferase

12 reaction method. In 3,5-di-O-CQA-treated SH-SY5Y cells, luminescence was significantly

13 upregulated by $113 \% \pm 7.2$ compared to non-treated group $(P<0.05)$ (Fig. 4$)$.

\section{Effect of CQA on spatial learning and memory of SAMP8 mice in MWM}

16 We measured the time, swimming time to arrive at the platform (escape latency time), to

17 assess the effect of 3,5-di-O-CQA on spatial learning and memory, which is AD's major

18 symptom. We noted that the 3 month-old SAMP8 and SAMR1 mice demonstrated

19 significant differences in motivational swimming speed between groups (data not shown).

20 As shown in Fig. 5, all groups (SAMP8, SAMP8+CQA, SAMR1 group) improved their

21 performance after 30 days. However, the escape latency time of SAMP8 group ( $n=10)$ was

22 slightly decreased, compared with SAMR1 and SAMP8+CQA groups. The escape latency 
1 time of SAMP8+CQA and SAMR1 group $(n=10)$ was significantly decreased compared to

2 SAMP8 group $(P<0.01)$. There was no significant difference between SAMP8+CQA and

3 SAMR1group on the escape latency time.

4

\section{Effect of CQA on the mRNA expression level of PGK1 on SAMP8 mice brain}

6 We investigated the mRNA expression level of PGK1 on SAMP8 mice brain to determine

7 the effect of 3,5-O-di CQA on PGK1 expression in vivo. From the real-time PCR result

8 (Fig. 6), the mRNA expression level of PGK1 was highly increased in the brain of 3,5-di-

9 O-CQA administrated SAMP8 mice. In fact, the PGK1 mRNA expression in

10 SAMP8+CQA group was significantly upregulated by $153 \% \pm 7.5$ compared with the

11 SAMR1 group $(P<0.01)$. However, the PGK1 mRNA expression in SAMP8 group was

12 slightly down-regulated compared to SAMR1 group (not significantly).

\section{DISCUSSION}

15 The pathogenesis of $\mathrm{AD}$ has been reported by several researchers who carried out post-

16 mortem determinations. $\mathrm{AD}$ is induced by: (1) a cholinergic defect; (2) a glutamatergic

17 impairment; (3) chromosome 21 impairment which produces $\beta$-APP; and (4) the

18 endothelium impairment of blood-brain barrier (BBB) (Hagino et al., 2004). Senile

19 dementia is a disease involving a cholinergic defect which is the direct result of the

20 decreased glucose metabolism in the brain (Meier-Ruge et al., 1984). Since the key

21 substrate of acetylcholine synthesis is acetylcoenzyme A, which is exclusively synthesized

22 in the glycolytic pathway in the brain. Glucose matabolism, final products of which are 
1 ATP and NADH, is the main fuel for all brain cells. The cholinergic defect, nerve cell death

2 and the amyloid protein accumulation in the brain may be a secondary phenomena caused

3 by the decline in glucose metabolism in senile dementia (Benson et al., 1983; Tucek et al., 4 1990).

5 In the presence of oxygen, glucose undergoes complete combustion to create $\mathrm{CO}_{2}$

6 and $\mathrm{H}_{2} \mathrm{O}$. The energy produce reaction that liberates free energy, which is trapped as ATP

7 into two consecutive processes: glycolysis and oxidative phosphorylation in mitochondria.

8 The impairment of glycolytic metabolism of glucose in the endothelium of $\mathrm{BBB}$, and the

9 dysfunction of glycolysis pathway cause hypoglycemia in the brain which may initiate the

10 accumulation of amyloid protein in the brain (Hagino et al., 2004).

11 Our results show that 3,5-di-O-CQA induced the intracellular ATP level in the

12 human neuroblastoma clonal SH-SY5Y cells. Moreover, 3,5-di-O-CQA induced the

13 overexpression of PGK1 mRNA on in vivo and in vitro. From these results, we suggest that

14 the increase of intracellular ATP level is caused by overexpression of PGK1 mRNA in 3,5-

15 di-O-CQA treatment. Therefore, it is possible that the neuroprotective effect of CQA is

16 closely related to the energy metabolism activation, glycolysis pathway activation via the

17 overexpression glycolytic enzyme.

CQA has a variety of physiological activities, antioxidant activity, cell

19 differentiation, analgesic activity and neuroprotective effect. However, there has been no

20 report that CQA induced the activation of ATP production in neuronal cells. Our study is

21 the first report on the new function of CQA as a stimulator of ATP production. Exposure of

22 neuronal cells to the strict circumstance, such as cell toxic and chronic hypoxia stimulates 
1 the expression of glucose transporters and enzymes that accelerate glucose utilization to

2 compensate for the reduced production of ATP (Gao et al., 2004). Such a response is

3 gradually late and weak in aging cells. From our results, we suggest that CQA contribute to

4 the homeostasis of ATP production in cells, especially on neuronal cells.

5 Futhermore, glycolytic enzymes have glycolytic and non-glycolytic functions. As

6 for the non-glycolytic functions, glycolytic enzymes play an important role in: (1)

7 apoptosis; (2) transcriptional regulation; (3) cell motility (Kim et al., 2005; Canback et al.,

8 2002). Some glycolytic enzymes, Hexokinase, GAPD, etc, are implicated in neuronal

9 apoptosis, and several groups have been investigating thier possible roles in age-related

10 neurodegenerative disorders such as AD (Zheng et al., 2003; Sirover et al., 1999; Mazzola

11 et al., 2003). These findings suggest that the activated glycolytic enzymes by CQA

12 treatment were related to the regulation of neuronal cell apoptosis via apoptosis regulator;

13 BAD, Bak and Bcl.

14 The parameter of spatial learning and memory (means of escape latency time to find

15 the hidden platform) within 6 days in MWM in SAMP8 and SAMR1 mice was similar.

16 However, 3,5-di-O-CQA, $6.7 \mathrm{mg} / \mathrm{kg} \cdot$ day, were shown to have decreased escape latency

17 time compared to the vehicle-administrated SAMP8 mice for 10-30 days. This dose of 3,5-

18 di-O-CQA also caused an increase in PGK1 mRNA expression in SAMP8 mice brains (Fig.

19 6). From these results, 3,5-di-O-CQA induced the overexpression of PGK1 mRNA level

20 both in vitro and in vivo.

21 Particularly, PGK1 is an important glycolytic enzyme because this enzyme that

22 induces the production of 2 molecules of ATP in glycolysis pathway. Furthermore, PGK1 
1 is not a rate limiting enzyme which is Hexokinase, Phosphofructokinase, Pyruvate kinase,

2 in the glycolysis pathway (Theresa et al., 1982). Therefore, the activation of PGK1 enzyme

3 is not affected by the feedback inhibition on ATP production. We suggest that 3,5-di-O-

4 CQA can induced the activation of ATP production without feedback inhibition through the 5 activation of PGK1.

6

\section{CONCLUSION}

8 In conclusion, we found that 3,5-di CQA has a neuroprotective effect on $A \beta_{1-42}$

9 treated SH-SY5Y cells. The mRNA expression of glycolytic enzyme (PGK1) and the

10 intracellular ATP level were increased in 3,5-di-O-CQA-treated SH-SY5Y cells. We also

11 found that 3,5-di-O-CQA administration induced the improvement of spatial learning and

12 memory on SAMP8 mice, and the overexpression of PGK1 mRNA level. These findings

13 suggest that 3,5-di-O-CQA has a neuroprotective effect through the induction of PGK1

14 expression and ATP production activation.

15 


\section{REFERNCES}

2 Angenstein F, Evans AM, Settlage RE, Moran ST, Ling S, Klintsova AY, Shabanowitz J,

3 Hunt DF, Greenough WT (2002) A receptor for activated C kinase is part of messenger

4 ribonucleoprotein complexes associated with polyA-mRNAs in neurons. J Neurosci 22:

$5 \quad 8827-8837$.

6 Basnet P, Matsushige K, Hase K, Kadota S, Namba T (1996) Four di-O-caffeoyl quinic

7 acid derivatives from propolis. Potent hepatoprotective activity in experimental liver

8 injury models. Biol Pharm Bull 19: 1479-1484.

9 Beal M.F (1995) Aging, energy, and oxidative stress in neurodegenerative diseases. Ann $10 \quad$ Neurol 38: 357-366.

11 Benson DF, Kubl DE, Hawkins RA, Phelps ME, Cumminge JL, Tsai SY (1983) The

12 fluorodeoxyglucose 18F scan in Alzheimer's disease and multi-infarct dementia. Arch $13 \quad$ Neurol 40: 711-714.

14 Blass JP, Sheu RK, Cedarbaum JM (1988) Energy metabolism in disorders of the nervous 15 system. Rev Neurol (Paris) 144: 543-563.

16 Boyd-kimball D, Sultana R, Fai Poon H, Lynn BC, Casamenti F, Pepeu G, Klein JB, 17 Butterfield DA (2005) Proteomic identification of proteins specifically oxidized by 18 intracerebeal injection of amyloid $\beta$-peptide (1-42) into rat brain: implications for 19 Alzheimer’s disease. Neurosci 132: 313-324.

20 Canback B, Andersson SGE, Kurland CG (2002) The global phylogeny of glycolytic 21 enzymes. Proc Natl Acad Sci USA 99: 6097-6102.

22 Eckert A, Marques CA, Keil U, Schussel K, Muller WE (2003) Increased apoptotic cell 
death in sporadic and genetic Alzheimer’s disease. Ann NY Acad Sci 1010: 604-609.

Fai Poon H, Farr SA, Thongboonkerd V, Lynn BC, Banks WA, Morley JE, Klein JB,

3 Butterfield DA (2005) Proteomic analysis of specific brain proteins in aged SAMP8

4 mice treated with alpha-lipoic acid: implications for aging and age-related

5 neurodegenerative disorders. Neurochemistry International 46: 159-168.

6 Fai Poon H, Joshi G, Sultana R, Farr SA, Banks WA, Morley JE, Calabrese V, Butterfield

7 DA (2004) Antisense directed at the A-beta region of APP decreases brain oxidative

8 markers in aged senescence accelerated mice. Brain Res 1018: 86-96.

9 Ferhat L, Charton G, Represa A, Ben Ari Y, Terrossian E, Khrestchatisky M (1996) Acidic

10 calponin cloned from neural cells is differentially expressed during rat brain

11 development. Eur J Neurosci 8: 1501-1509.

12 Gao L, Mejías R, Echevarría M, López-Barneo J (2004) Induction of the glucose-6-

13 phosphate dehydrogenase gene expression by chronic hypoxia in PC12 cells. FEBS

$14 \quad$ Letters 569: 256-260.

15 Haag J, Aigner T (2007) Identification of calponin 3 as a novel Smad-binding modulator of 16 BMP signaling expressed in cartilage. Experimental cell reseach 313: 3386-3394.

17 Hagino N, Kobayashi S, Tsutsumi T, Horiuchi S, Nagai R, Setalo G, Dettrich E (2004)

18 Vascular change of hippocampal capillary is associated with vascular change of retinal 19 capillary in aging. Brain Research Bulletin 62: 537-547.

20 Holliday R (1996) The urgency of research on ageing. Bioessays 18: 89-90.

21 Hosokawa M, Abe T, Higuchi K, Shimakawa K, Omori Y, Matsushita T, Kogishi K, 22 Deguchi E, Kishimoto Y, Yasuoka K, Takeda T (1997) Management and design of the 
maintenance of SAM mouse strains: an animal model for accelerated senescence and ageassociated disorders. Exp Gerontol 32: 111-116.

3 Huang F, Li W, Zhang B, Cui X, Han Z, Fang Z, Cai S, Yin L, Wang L (2001) Effects of 4 free radicals and amyloid beta protein on the currents of expressed rat receptors in $5 \quad$ Xenopus oocytes. Chin Med J (Engl.) 114: 244-247.

6 Hur JY, Soh Y, Kim BH (2001) Neuroprotective and neurotrophic effects of quinic acids 7 from Aster scaber in PC12 cells. Biol Pharm Bull 24: 921-924.

8 Isoda H, Talorete TPN, Han J, Nakamura K (2006) Expresion of galectin-3, glutathione S9 transferase A2 and peroxiredoxin-1 by nonylphenol-incubated Caco-2 cells and 10 reduction in transepithelial electrical resistance by nonylphenol. Toxicology in Vitro $1120: 63-70$.

12 Kim JW, Dang CV (2005) Multifaceted roles of glycolytic enzymes. Trends in Biochemical 13 Sciences: $30,142-150$.

14 Kwon YS, Kim KO, Lee JH (2003) Chemical constituents of Dipsacus asper (II). Kor J 15 Pharmacogn 34: 128-131.

16 Kumar VB, Farr SA, Flood JF, Kamlesh V, Franko M, Banks WA, Morley JE (2000) Site17 directed antisense oligonucleotide decreases the expression of amyloid precursor 18 protein and reverses deficits in learning and memory in aged SAMP8 mice. Peptides $19 \quad 21: 1769-1775$.

20 Li Q, Zhao HF, Zhang ZF, Liu ZG, Pei XR, Wang JB, Li Y (2009) Long-term green tea 21 catechin administration prevents spatial learning and memory impairment in 22 senescence-accelerated mouse prone- 8 mice by decreasing $A \beta_{1-42}$ oligomers and 
1 upregulating synaptic plasticity-related proteins in the hippocampus. Neurosci 163 :

$2 \quad 741-749$.

3 Li YP, Bushnell AF, Lee CM, Perlmutter LS, Wong SKF (1996) $\beta$-Amyloid induces 4 apoptosis in human-derived neurotypic SH-SY5Y cells. Brain Research 738: 196-204.

5 Martínez T, Pascual A (2007) Identification of genes differentially expressed in SH-SY5Y

6 neuroblastoma cells exposed to the prion peptide 106-126. Eur J Neurosci 26: 51-59.

7 Mazzola JL, Sirover MA (2003) Subcellular alteration of glyceraldehyde-3-phosphate

8 dehydrogenase in Alzheimer’s disease fibroblasts. J Neurosci Res 71: 279-285.

9 Meier-Ruge W, Hunziker O, Iwangoff P (1991) Senile dementia: a threshold phenomenon

10 of normal aging? A contribution to the functional reserve hypothesis of the brain. Ann

$11 \quad$ NY Acad Sci 621: 104-118.

12 Nakajima Y, Shimazawa M, Mishima S, Hara H (2007) Water extract of propolis and its

13 main constituents, caffeoylquinic acid derivatives, exert neuroprotective effects via 14 antioxidant actions. Life sciences 80: 370-377.

15 Nomura Y, Yamanaka Y, Kitamura Y, Arima T, Ohnuki T, Oomura Y, Sasaki K, 16 Nagashima K, Ihara Y (1996) Senescence-accelerated mouse. Neurochemical studies 17 on aging. Ann NY Acad Sci 786: 410-418.

18 Morley JE, Kumar VB, Bernardo AE, Farr SA, Uezu K, Tumosa N, Flood JF (2000) Beta19 amyloid precursor polypeptide in SAMP8 mice affects learning and memory. Peptides $20 \quad 21: 1761-1767$.

21 Ohta A, Hirano T, Yagi H, Tanaka S, Hosokawa M, Takeda T (1989) Behavioral 22 characteristics of the SAM-P/8 strain in Sidman active avoidance task. Brain Res 498: 
195-198.

2 Qi X, Xiu J, Shan K, Xiao Y, Gu R, Liu R, Guan Z (2005) Qxidative stress induced by

3 beta-amyloid peptide $e_{1-42}$ is involved in the altered composition of cellular membrane

4 lipids and the decreased expression of nicotinic receptors in human SH-SY5Y

5 neuroblastoma cells. Neurochem inter 46: 613-621.

6 Roth KA (2001) Caspases, apoptosis, and Alzheimer disease: causation, correlation, and

$7 \quad$ confusion. J Neuropathol Exp Neurol 60: 829-838.

8 Shapiro TA, Talalay P (1982) Schistosoma mansoni: Mechanisms in regulation of 9 glycolysis. Experimental Parasitology 54: 379-390.

10 Shimano Y (1998) Studies on aging through analysis of the glucose metabolism related to 11 the ATP-production of the senescence accelerated mouse (SAM). Hokkaido Igaku 12 Zasshi 73: 557-569.

13 Sirover MA (1999) New insights into an old protein: the functional diversity of mammalian

14 glyceraldehyde-3-phosphate dehydrogenase. Biochim Biophys Acta 1432: 159-184.

15 Soh Y, Kim JA, Sohn NW, Lee KR, Kim SY (2003) Protective effects of quinic acid 16 derivatives on tetrahydropapaveroline induced cell death in C6 glioma cells. Biol Pharm $17 \quad$ Bull 26: 803-807.

18 Takeda T, Hosokawa M, Takeshita S, Irino M, Higuchi K, Matsushita T, Tomita Y, 19 Yasuhira K, Hamamoto H, Shimizu K, Ishii M, Yamamuro T (1981) A new murine 20 model of accelerated senescence. Mech Ageing Dev 17: 183-194.

21 Tucek S, Rincy J, Dolazal V (1990) Advance in the biology of cholinergic neurons. Adv $22 \quad$ Neurol 51: 109-115. 
1 Wang H, Xu Y, Yan J, Zhao X, Sun X, Zhang Y, Guo J, Zhu C (2009) Acteoside protects

2 human neuroblastoma SH-SY5Y cells against $\beta$-amyloid-induced cell injury. Brain

$3 \quad$ Research 1283: 139-147.

4 Yagi H, Katoh S, Akiguchi I, Takeda T (1988) Age-related deterioration of ability of 5 acquisition in memory and learning in senescence accelerated mouse: SAM-P/8 as an $6 \quad$ animal model of disturbances in recent memory. Brain Res 474: 86-93.

7 Zheng L, Roeder RG, Luo Y (2003) S phase activation of the histone H2B promoter by 8 OCA-S, a coactivator complex that contains GAPDH as a key component. Cell 114: $9 \quad 255-266$. 
1 Fig. 1

2

3

4

5

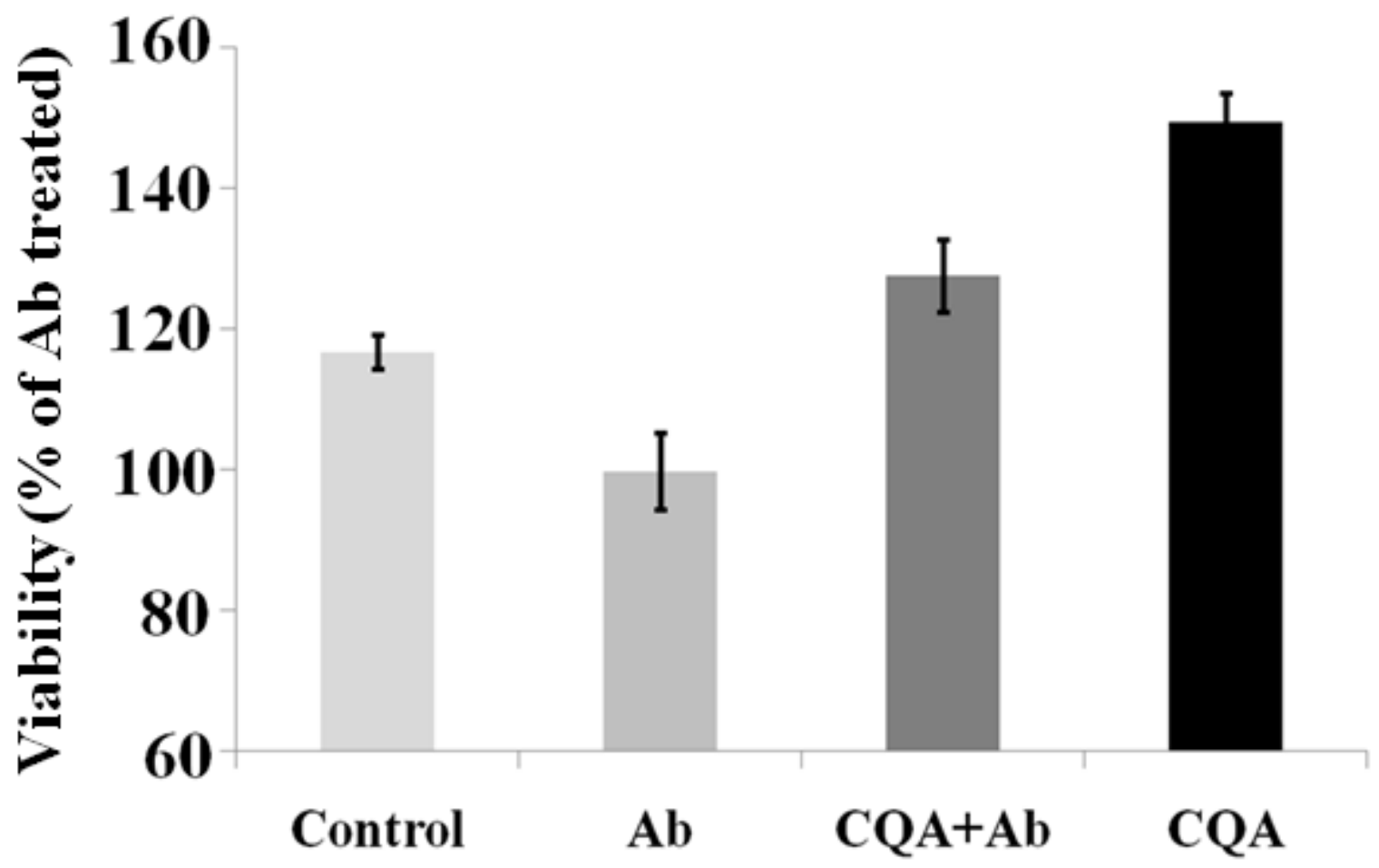

6

7

8

9

10

11

12 
1 Fig. 2

A

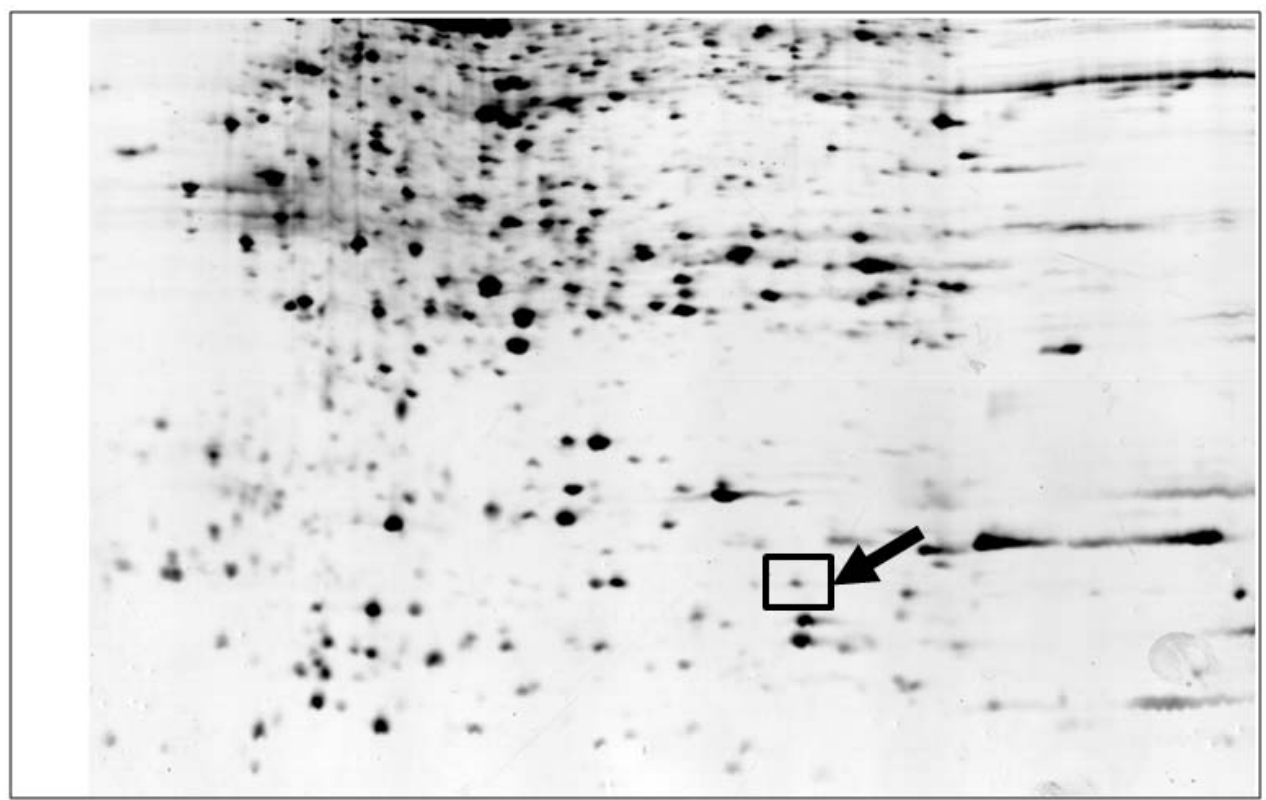

2
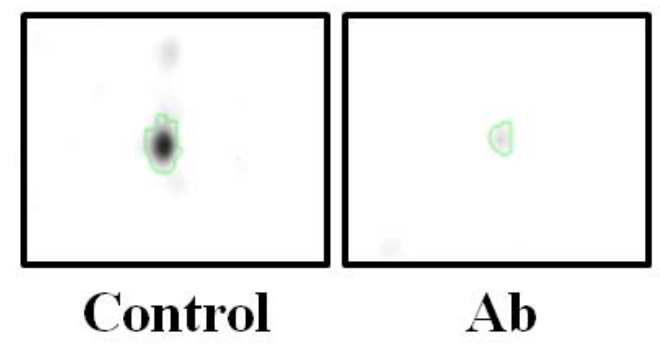

Ab
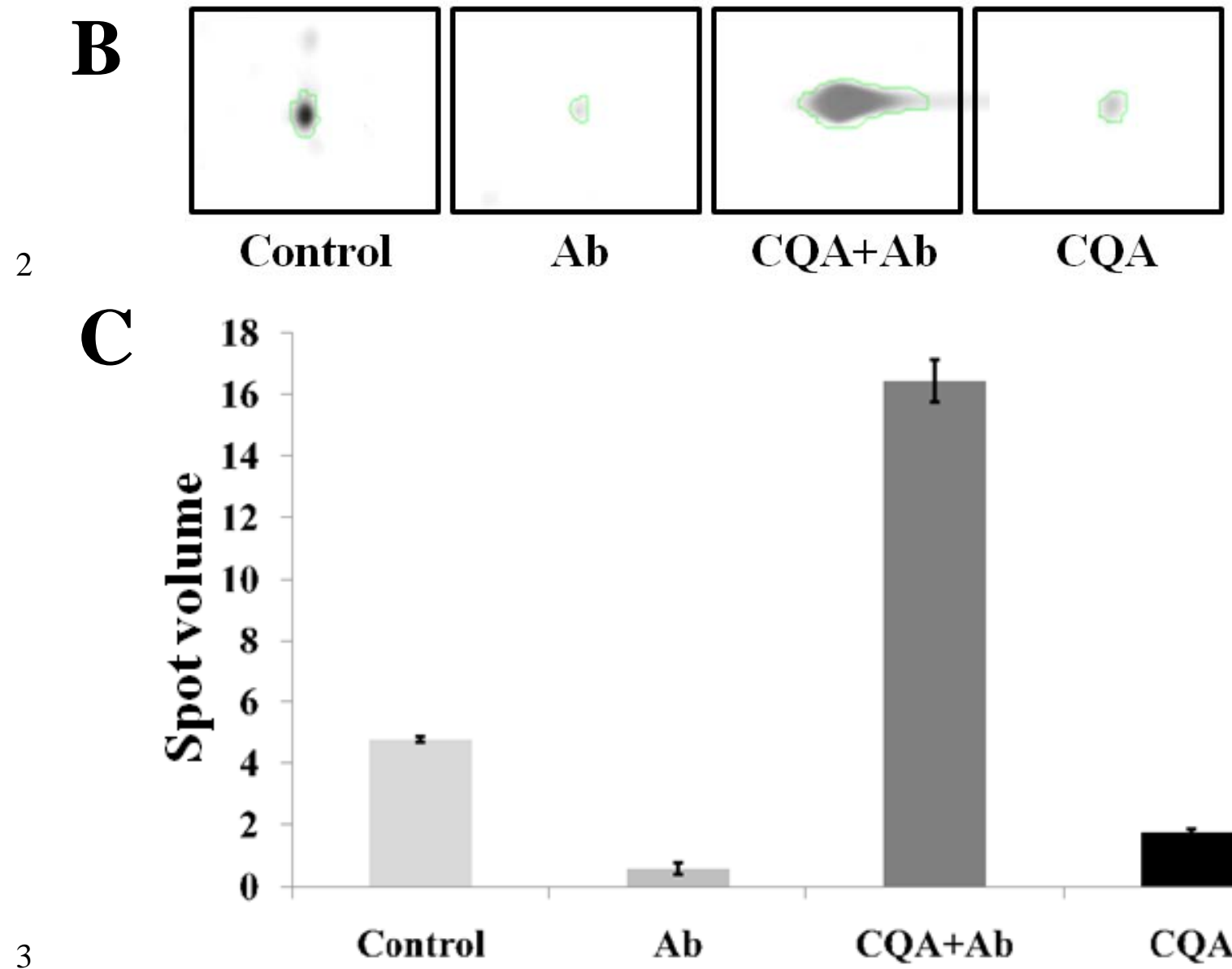

18

16

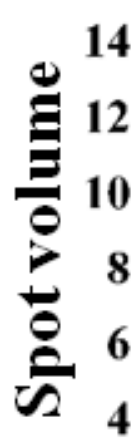

4
2

0

$\left.\begin{array}{l}18 \\ 16 \\ 1 \\ 0 \\ 8 \\ 6 \\ 4 \\ 2 \\ 0\end{array}\right]$
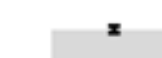
1
2
3
4
5
6

Fig. 3

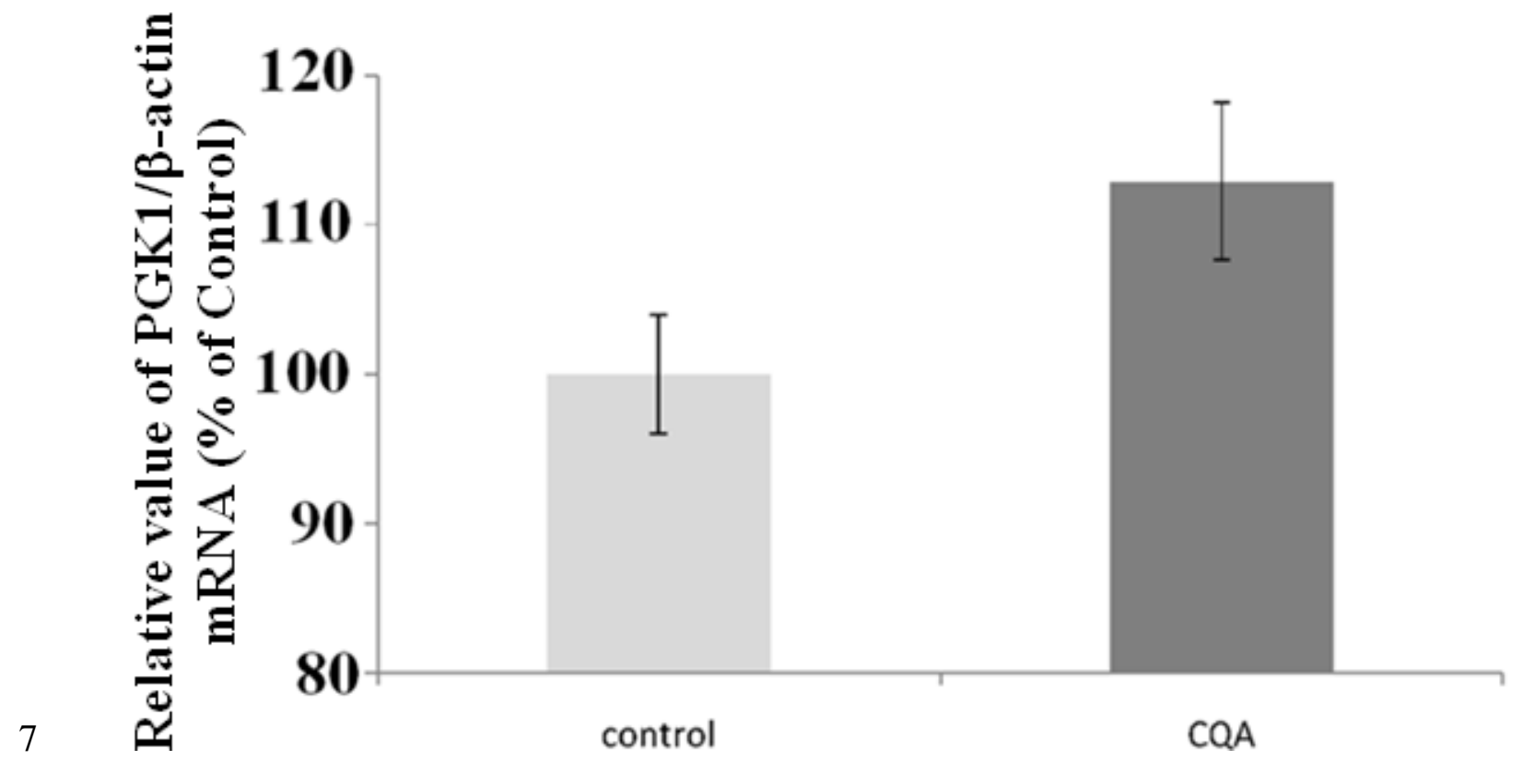

8

9

10

11

12

13

14 
$1 \quad$ Fig. 4

2

3

4

5

6

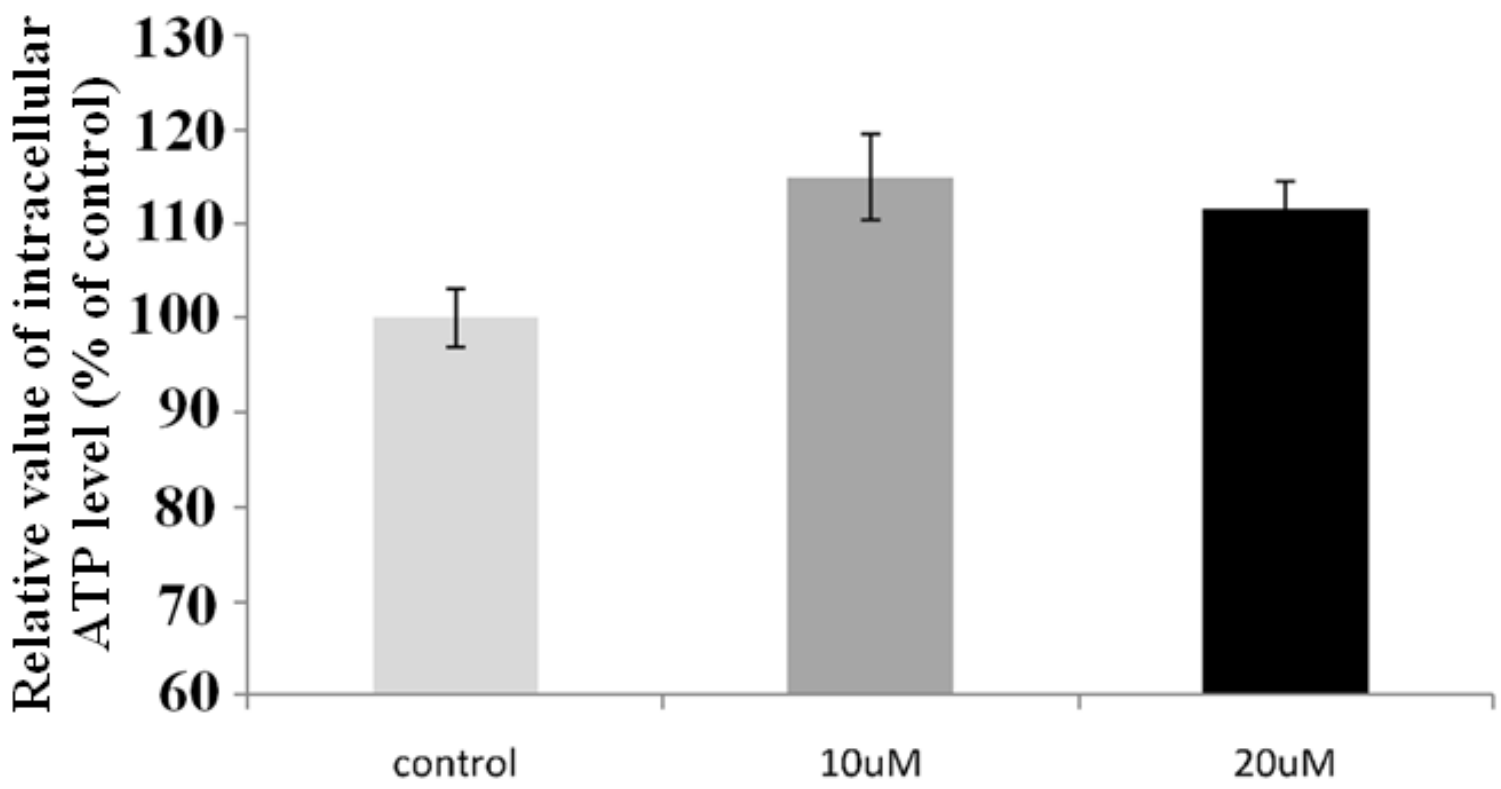

8 
1 Fig. 5

2

3

4

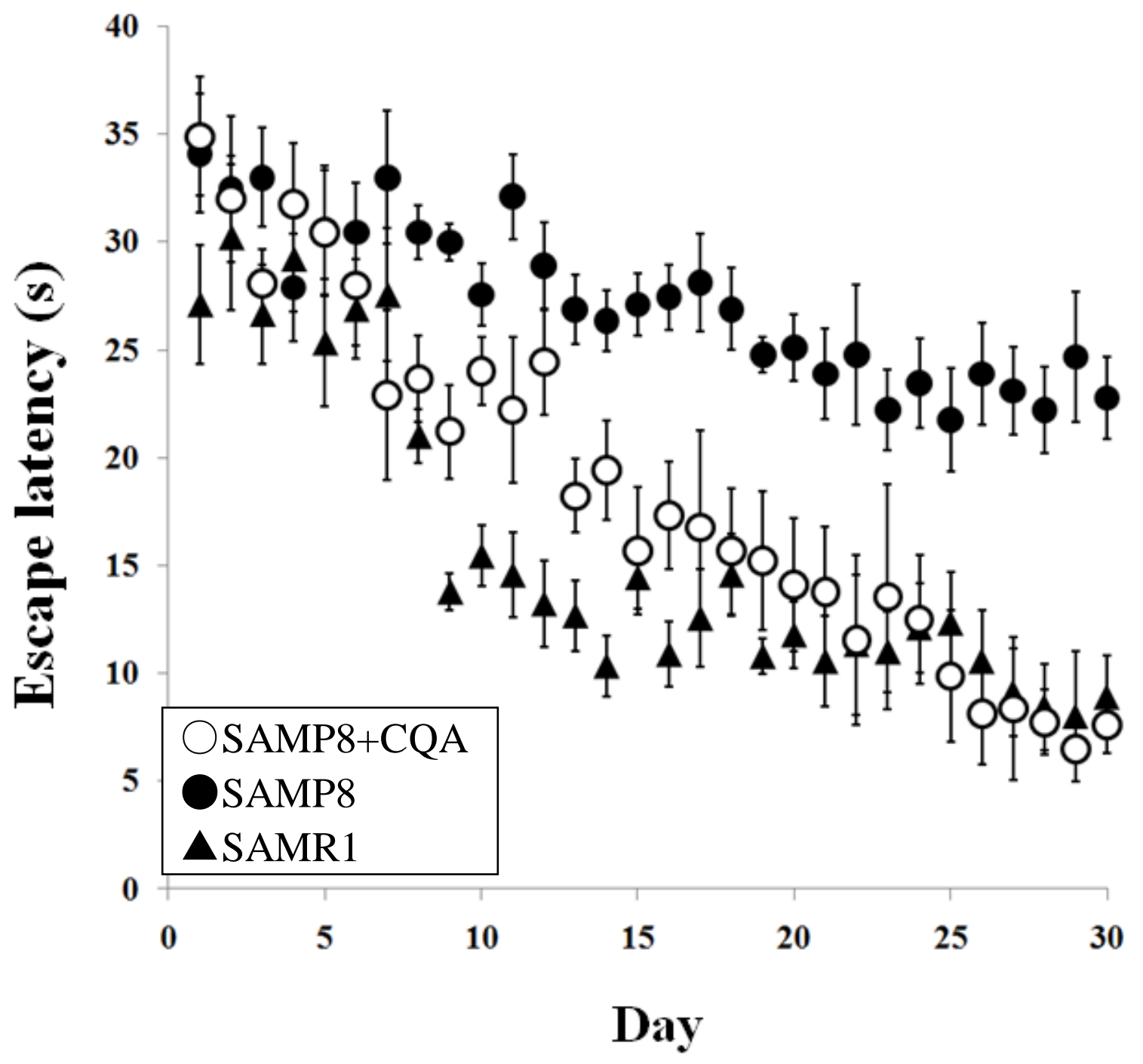

6 
$1 \quad$ Fig. 6

2

3

4

5

6

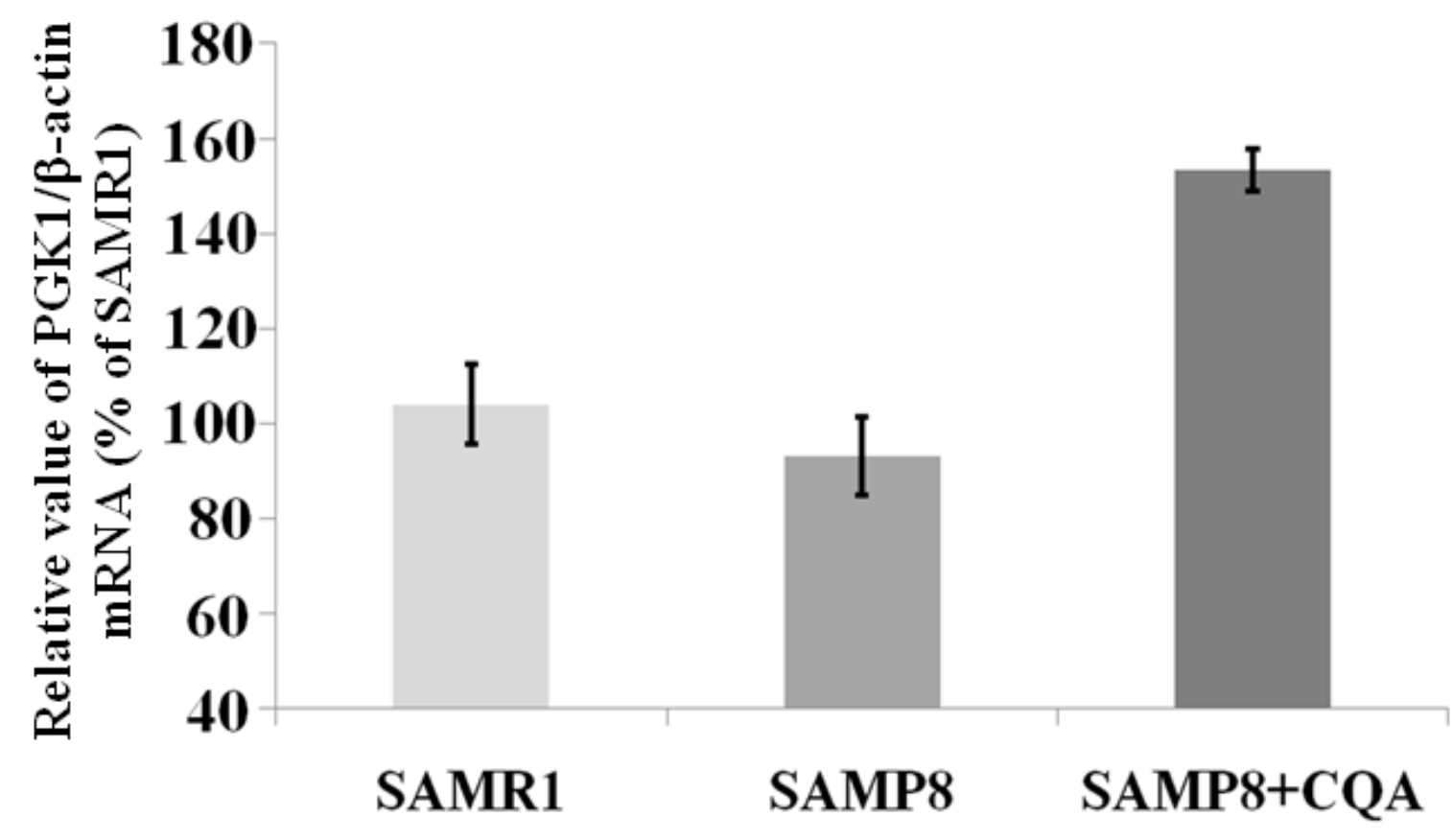

7

8

9

10

11

12

13

14 
1 Fig. 1 Effect of 3,5-di-O-CQA on the $A \beta_{1-42}$ treated SH-SY5Y cells viability. SH-SY5Y

Fig. 2 Two-dimensional gel electrophoresis of SH-SY5Y cells (A), the magnified images of the boxed regions (B) and spot volume (C). SH-SY5Y cells were treated with $20 \mu \mathrm{M}$ 3,5-di-O-CQA or exposed to $2 \mu \mathrm{M} A \beta_{1-42}$ for $72 \mathrm{~h}$,. The 2-DE gel was stained with coomassie brilliant blue. Spot volume was measured by ImageMaster 2D Platinum software. These spots were identified as PGK1 by MALDI-TOF mass spectrometry. Each bar represents the mean $\pm \mathrm{SD}(n=3) .{ }^{* *} P<0.01$ (vs control).

Fig. 3 Effect of 3,5-di-O-CQA on the expressions of PGK1 mRNAs by SH-SY5Y cells. $\beta$ actin was used as a housekeeping gene. The mRNA expression of PGK1 was normalized by $\beta$-actin mRNA expression. SH-SY5Y cells were treated with $10 \mu \mathrm{M}$ 3,5-di-O-CQA for $16 \mathrm{~h}$. Each bar represents the mean $\pm \mathrm{SD}(n=4) . * P<0.05$

Fig. 4 Effect of 3,5-di-O-CQA on the intracellular ATP production of SH-SY5Y cells. SHSY5Y cells were treated with 10 and $20 \mu \mathrm{M}$ 3,5-di-O-CQA for $48 \mathrm{~h}$. Intracellular ATP production was increased by 3,5-di-O-CQA treatment on SH-SY5Y cells. Each bar represents the mean $\pm \operatorname{SD}(n=10) . * * P<0.01$ vs control 
1 Fig. 5 Effect of 3,5-di-O-CQA on the spatial learning and memory of SAMP8 mice in 2 MWM. The average time to reach the hidden platform (latency in seconds) is plotted 3 for each training day. SAMP8 mice were administrated with 3,5-di-O-CQA (6.7 $4 \mathrm{mg} / \mathrm{kg} \cdot$ day) for 30 days. Each bar represents the mean \pm SD $(n=8) .{ }^{*} P<0.05$ vs $5 \quad$ SAMP8 group.

7 Fig. 6 Effect of 3,5-di-O-CQA on the expressions of PGK1 mRNAs by SAMR1 and $8 \quad$ SAMP8 mice brains. $\beta$-actin was used as a housekeeping gene. The mRNA expression 9 of PGK1 was normalized by $\beta$-actin mRNA expression. SAMP8 mice were 10 administrated with 3,5-di-O-CQA (6.7 mg/kg • day) for 30 days. Each bar represents 11 the mean $\pm \operatorname{SD}(n=8) . * P<0.05$ 